\title{
A new approach to the characterization of Streptococcus salivarius subsp thermophilus based on acidification rates
}

\author{
P Zanatta, A Basso \\ Istituto Lattiero Caseario e di Biotecnologie Agroalimentari di Thiene, \\ Via S Gaetano, 74, 36016, Thiene, Vicenza, Italy
}

(Received 5 July 1991; accepted 13 February 1992)

\begin{abstract}
Summary - Thirty-seven strains of Streptococcus salivarius subsp thermophilus, isolated from Italian local cheeses and natural starters were characterized on the basis of 6 parameters of their acidification abilities obtained from $\mathrm{pH}$ changes in milk as a function of time. Data were evaluated using principal component analysis (PCA), which emphasized the differences between the strains and allowed them to be divided into 3 groups. The differences observed in the analytical procedure were verified in cheesemaking, in which 2 starter cultures composed of strains from 2 different groups were used. Curd acidification rates were different, confirming the validity of the classification.
\end{abstract}

acidification / Montasio cheese / SIMCA / starter / Streptococcus salivarius subsp thermophilus

Résumé - Une nouvelle approche pour la caractérisation de Streptococcus salivarius subsp thermophilus basée sur la vitesse d'acidification. Le pouvoir acidifiant de 37 souches de Streptococcus salivarius subsp thermophilus, isolées de levains naturels et de fromages a été étudié, utilisant 6 paramètres dérivés des courbes d'acidification $(\mathrm{pH} / \mathrm{temps})$. Les données ont été traitées par analyse en composantes principales (ACP). Ce traitement, qui a mis en évidence une grande diversité parmi les souches, a permis une répartition des micro-organismes en 3 groupes. Au moyen de quelques essais pratiques en fromagerie les souches des 2 groupes ont été comparées. Il a été remarqué une étroite corrélation entre les différences mises en évidence par le traitement des données et les caractéristiques des fromages produits.

acidification / fromage Montasio / levain / SIMCA / Streptococcus salivarius subsp thermophilus 


\section{INTRODUCTION}

Lactic acid production is the most important feature of cheese starter cultures, affecting several aspects of cheese manufacture such as coagulant activity, denaturation and retention of the coagulant in the curd during manufacture, curd strength, rheological properties and inhibition of non starter and pathogenic bacteria (Cogan and Daly, 1987). The diversity of cheese varieties is the result of different technologies employed in cheesemaking processes; acidification rate, final $\mathrm{pH}$ value and temperature (eg cooking and ripening temperatures) are some of the most critical factors involved.

The methods available for quantifying the starter activity are usually based on $\mathrm{pH}$ changes as a function of time (Accolas and Auclair, 1970; FIL/IDF, 1980; Heap and Lawrence, 1981; Coppola et al, 1990; Jones et al, 1990), or lactic acid production measured by titration with $\mathrm{NaOH}$ (Horral and Elliker, 1947; Accolas and Auclair, 1970; FILIDF, 1980), or determination of lactic acid per se (Nielsen et al, 1989; Forni et al, 1990). These methods consider the value of the parameter after a predetermined time, but a general view of the acidification process is usually not examined. This could give rise to loss of information on the activity of a particular strain and make comparisons of different strains more difficult.

In a recent study, Spinnler and Corrieu (1989) proposed a new method for the determination of acidification activity based on measuring the $\mathrm{pH}$ of cultures at extremely short intervals and calculating several kinetic parameters such as the time and $\mathrm{pH}$ at which the maximum acidification rate $\left(V_{m}\right)$ is achieved and the time and the $\mathrm{pH}$ range during which the rates were greater than $V_{\mathrm{m}} / 2$.

We assumed that this approach, which generates a description of the acidification behaviour of each strain could be used as an appropriate tool for classifying a large number of strains by applying chemometric techniques based on multivariate statistical analysis. Accordingly, we focused our interest on a number of strains of Streptococcus salivarius subsp thermophilus, isolated from local cheeses and natural starter cultures, with the aim of verifying whether they could be classified in groups and compared with commercial strains.

\section{MATERIALS AND METHODS}

\section{Microorganisms and growth conditions}

Thirty-seven strains of Streptococcus salivarius subsp thermophilus from the collection of Istituto Lattiero Caseario e di Biotecnologie Agroalimentari di Thiene were used. These were isolated from samples of cheeses and natural starter cultures in 8 cheese factories of the Veneto and Friuli Venezia Giulia regions of Italy. Commercial strains were obtained from thermophilic commercial cultures.

All the strains were isolated from a single colony in Petri dishes containing litmus milk agar ( $10 \mathrm{~g}$ of litmus milk and $2 \mathrm{~g}$ of agar were each dissolved separately in $47 \mathrm{ml}$ of water and sterilized at $110^{\circ} \mathrm{C}$ for $10 \mathrm{~min}$ before mixing) after anaerobic incubation at $37^{\circ} \mathrm{C}$ for 3 days. The bacteria were identified using Bergey's Manual of Systematic Bacteriology (Hardie, 1986), according to the recent taxonomic changes (Farrow and Collins, 1984; Moore and Moore, 1989), and stored at $-80^{\circ} \mathrm{C}$ in $\mathrm{M} 17$ broth (Terzaghi and Sandine, 1975) supplemented with $1 \%$ peptonized milk (Oxoid) and 15\% (v/v) glycerol.

For the experiment, strains were thawed and transferred to Petri dishes containing litmus milk agar and incubated anaerobically for 3 days at $37{ }^{\circ} \mathrm{C}$. A $1-\mu l$ loopful $(O D=1.2$ at $620 \mathrm{~nm}$ after resuspension in $1 \mathrm{ml}$ of Ringer's solution) of bacteria was incubated in $100 \mathrm{ml}$ of $10 \%(\mathrm{w} / \mathrm{v})$ reconstituted dried skim milk previously sterilized at $105^{\circ} \mathrm{C}$ for $5 \mathrm{~min}$, and incubated at $44^{\circ} \mathrm{C}$ until an acidity level of $10^{\circ} \mathrm{SH} / 50 \mathrm{ml}$ was reached. Cultures were immediately cooled in water and stored at $4{ }^{\circ} \mathrm{C}$ for $1 \mathrm{~h}$ before use. 
Acidification tests were carried out in 250-ml glass bottles (Pyrex; J Bibby Products Ltd, UK) containing $200 \mathrm{ml}$ of $10 \%$ (W/v) reconstituted dried skim milk from the same lot of powder, sterilized at $105^{\circ} \mathrm{C} \times 5 \mathrm{~min}$ and inoculated with $4 \mathrm{ml}$ of the culture. The bottles were incubated at $37^{\circ} \mathrm{C}$ for $30 \mathrm{~min}$ and subsequently transferred to $44{ }^{\circ} \mathrm{C}$ for the following $18 \mathrm{~h}$. The $\mathrm{pH}$ was measured by introducing the electrodes, disinfected with ethanol, through holes in the screw cap.

\section{Data acquisition and treatment}

The system used for data acquisition (MICROS; Conegliano, Italy) comprised a central acquisition and processing module, a peripheral module for data acquisition connected to $10 \mathrm{pH}$ meters and a CMOS static RAM memory module for data storage.

After calibration of the electrodes, the $\mathrm{pH}$ measurements were taken and stored at 2-min intervals. This frequency was sufficient to evaluate the kinetic parameters. At the end of the experiment, the $\mathrm{pH}$ data, stored in the static memory of the system, were transferred to a personal computer where the following 6 parameters were calculated: the maximum acidification rate $\left(V_{m}=\mathrm{dpH} / \mathrm{dt}\right)$, the time $\left(T_{\mathrm{m}}\right)$ and $\mathrm{pH}$ $\left(p H_{m}\right)$ at which the maximum acidification rate occurred, the time range $\left(T_{50}\right)$ and $\mathrm{pH}$ range $\left(\mathrm{pH}_{50}\right)$ in which the observed rates were greater than $V_{m} / 2$ (Spinnler and Corrieu, 1989) and the $\mathrm{pH}\left(\mathrm{pH}_{16}\right)$ reached after $16 \mathrm{~h}$, the latter being added to the 5 parameters suggested by Spinnler and Corrieu.

\section{Statistical analysis}

Data analysis was carried out by the SIMCA method based on principal components analysis (PCA). Multivariate techniques are far more powerful than univariate classification methods based on averages and standard deviations (Wold and Sjöström, 1977; Albano et al, 1978; Wold et al, 1983, 1984, 1987).

PCA is a multivariate statistical technique which permits transformation of data into informative plots, and determination if the data set is homogeneous or if it is formed by 2 or more groups of data points. The formulation of our problem is that of 37 strains (objects) in a 6dimensional space. PCA is used to find the relative position of these points in this space by reducing the dimensionality of the problem from 6 to 2 dimensions fitting a plane to the data points by a least-squares procedure. The resulting plot clearly indicates the existence of clusters, if any. PCA has been used for a long time in food chemistry classification problems (Wold et al, 1984; Clementi et al, 1990).

In fact, new objects can be fitted to each disjoint model for each class formed by homogeneous objects: the classification can be derived by examining the object-model distances.

In this study, computations have been carried out by the SIMCA package developed by Wold and Sjöström (1977).

\section{Experimental cheesemaking}

Experimental cheesemaking was carried out according to the manufacturing method for Montasio cheese, a typical semi-hard cheese of the Veneto and Friuli-Venezia-Giulia regions of Italy, partly modified by using a pasteurization treatment of $72^{\circ} \mathrm{C} \times 15 \mathrm{~s}$, in order to eliminate interference from milk microflora. An outline of the technology used for Montasio cheese manufacture is reported in figure 1.

Starter cultures were prepared by inoculation of $10 \%(w / v)$ reconstituted skim milk (sterilized at $\left.110{ }^{\circ} \mathrm{C} \times 10 \mathrm{~min}\right)$ with some of the strains studied (see table $\mathrm{V}$ ) and incubated at $44^{\circ}$ until an acidity level of $10^{\circ} \mathrm{SH} / 50 \mathrm{ml}$ was reached; milk was immediately cooled in water and stored overnight at $4{ }^{\circ} \mathrm{C}$. For each experiment, 2.5 I of culture composed of equal parts of the single strain cultures were added to $250 \mathrm{I}$ of milk at a temperature of $35^{\circ} \mathrm{C}$. Bacterial counts (CFU/ml) were carried out using the pour plate method and M17 agar supplemented with $10 \mathrm{~g} / \mathrm{l}$ peptonized milk (Oxoid) incubated anaerobically at 37 ${ }^{\circ} \mathrm{C}$ for 3 days. The $\mathrm{pH}$ of the cheese was measured using cheese $\mathrm{pH}$ electrodes (Ingold; LoT406 - M6 - DXK).

\section{RESULTS AND DISCUSSION}

The data set used is shown in table I; the last 3 strains were isolated from commer- 
Table I. Kinetic parameters (mean of 2 repetitions) of strains of Streptococcus salivarius subsp thermophilus.

Paramètres cinétiques (valeurs moyennes de 2 répétitions) des souches de Streptococcus salivarius subsp thermophilus.

\begin{tabular}{|c|c|c|c|c|c|c|c|}
\hline No & Strain & $\mathrm{V}_{m}{ }^{(1)}$ & $\mathrm{T}_{m}(2)$ & $\mathrm{pH}_{m}^{(3)}$ & $\mathrm{T}_{50^{(2)}}$ & $\mathrm{pH}_{50^{(3)}}$ & $\mathrm{pH}_{16}^{(3)}$ \\
\hline 1 & THT14 & -8.96 & 156 & 5.01 & 4000 & 1.82 & 4.05 \\
\hline 2 & THT15 & -11.04 & 124 & 4.99 & 364 & 2.04 & 3.80 \\
\hline 3 & THT16 & -10.68 & 130 & 4.98 & 368 & 1.99 & 3.85 \\
\hline 4 & ТНТЗ8 & -4.75 & 208 & 5.43 & 806 & 1.91 & 4.42 \\
\hline 5 & THT17 & -5.23 & 174 & 5.54 & 620 & 1.63 & 4.55 \\
\hline 6 & THT18 & -5.00 & 172 & 5.53 & 624 & 1.57 & 4.53 \\
\hline 7 & THT19 & -5.02 & 172 & 5.54 & 658 & 1.68 & 4.48 \\
\hline 8 & THT2O & -11.04 & 126 & 4.99 & 336 & 1.87 & 4.00 \\
\hline 9 & THT21 & -11.00 & 130 & 4.94 & 346 & 1.94 & 4.00 \\
\hline 10 & THT22 & -10.58 & 130 & 4.99 & 356 & 1.91 & 4.00 \\
\hline 11 & THT23 & -10.33 & 134 & 4.98 & 364 & 1.92 & 4.00 \\
\hline 12 & THT1 & -4.80 & 188 & 5.50 & 778 & 1.87 & 4.45 \\
\hline 13 & ТНТ39 & -5.27 & 164 & 5.50 & 610 & 1.63 & 4.40 \\
\hline 14 & THT40 & -5.26 & 178 & 5.38 & 688 & 1.82 & 4.35 \\
\hline 15 & THT2 & -5.08 & 168 & 5.52 & 648 & 1.65 & 4.40 \\
\hline 16 & THT3 & -5.20 & 162 & 5.52 & 682 & 1.78 & 4.42 \\
\hline 17 & THT33 & -2.15 & 270 & 5.75 & 932 & 1.17 & 5.11 \\
\hline 18 & THT36 & -2.24 & 498 & 5.27 & 1418 & 1.91 & 4.53 \\
\hline 19 & THT34 & -1.55 & 368 & 5.66 & 956 & 1.12 & 4.72 \\
\hline 20 & THT35 & -1.35 & 510 & 5.48 & 942 & 1.02 & 5.01 \\
\hline 21 & THT9 & -2.03 & 326 & 5.44 & 954 & 1.27 & 5.09 \\
\hline 22 & THT4 & -5.51 & 206 & 5.33 & 686 & 1.90 & 4.89 \\
\hline 23 & THT5 & -5.84 & 198 & 5.32 & 680 & 1.99 & 4.35 \\
\hline 24 & THT6 & -6.13 & 194 & 5.26 & 676 & 2.07 & 4.27 \\
\hline 25 & THT7 & -6.10 & 192 & 5.32 & 634 & 1.95 & 4.39 \\
\hline 26 & THT8 & -5.52 & 212 & 5.32 & 740 & 2.05 & 4.32 \\
\hline 27 & THT10 & -10.49 & 126 & 5.17 & 364 & 1.93 & 4.03 \\
\hline 28 & THT11 & -10.21 & 124 & 5.21 & 384 & 1.99 & 4.04 \\
\hline 29 & THT24 & -6.16 & 198 & 5.43 & 658 & 2.03 & 4.30 \\
\hline 30 & THT25 & -11.27 & 138 & 4.92 & 372 & 2.11 & 3.82 \\
\hline 31 & THT26 & -11.84 & 130 & 5.00 & 396 & 2.36 & 3.87 \\
\hline 32 & THT27 & -11.27 & 132 & 5.00 & 370 & 2.10 & 3.85 \\
\hline 33 & THT28 & -10.73 & 132 & 5.08 & 374 & 2.04 & 3.84 \\
\hline 34 & THT29 & -4.87 & 250 & 5.25 & 822 & 2.01 & 4.39 \\
\hline 35 & ТНT30 & -4.73 & 256 & 5.30 & 868 & 2.06 & 4.40 \\
\hline 36 & THT31 & -5.10 & 226 & 5.32 & 778 & 1.99 & 4.38 \\
\hline 37 & ТНТ32 & -4.96 & 240 & 5.29 & 810 & 2.01 & 4.39 \\
\hline 38 & THT12 & -6.20 & 154 & 5.53 & 620 & 1.93 & 4.38 \\
\hline 39 & THT13 & -7.53 & 144 & 5.41 & 564 & 2.14 & 4.19 \\
\hline 40 & ТНТ37 & -3.70 & 272 & 5.51 & 958 & 2.00 & 4.51 \\
\hline
\end{tabular}

(1) Expressed as $\mathrm{pH}$ milliunits/minute. (2) Expressed as minutes. (3) Expressed as $\mathrm{pH}$ unit.

(1) Exprimé en milliunité $\mathrm{pH}$ par minute. (2) Exprimé en fonction du temps (min). (3) Exprimé en unité pH. 
cial cultures. Each strain (object) is represented by a vector of 6 elements corresponding to the 6 parameters listed in the Data acquisition section. The parameters were derived from plots of $\mathrm{pH}$ vs time, change in $\mathrm{pH} / \mathrm{min}$ vs time and change in $\mathrm{pH} / \mathrm{min}$ vs $\mathrm{pH}$. Representative results from a fast, medium and slow strain (see below) are shown in figures 2 and 3.

The chemometric model was obtained by carrying out PCA on the 37 objects con- stituting the training set. The results of the analysis are reported in table II and figures 5 and 6 ; a 2-component model explains $85 \%$ of the total variance of the data matrix.

Figure 5 clearly shows that there are 3 distinct groups of strains corresponding to fast (F), medium (M) and slow (S) acidification rates, respectively. Their separation is found mainly along the first principal component, which can be seen as a linear

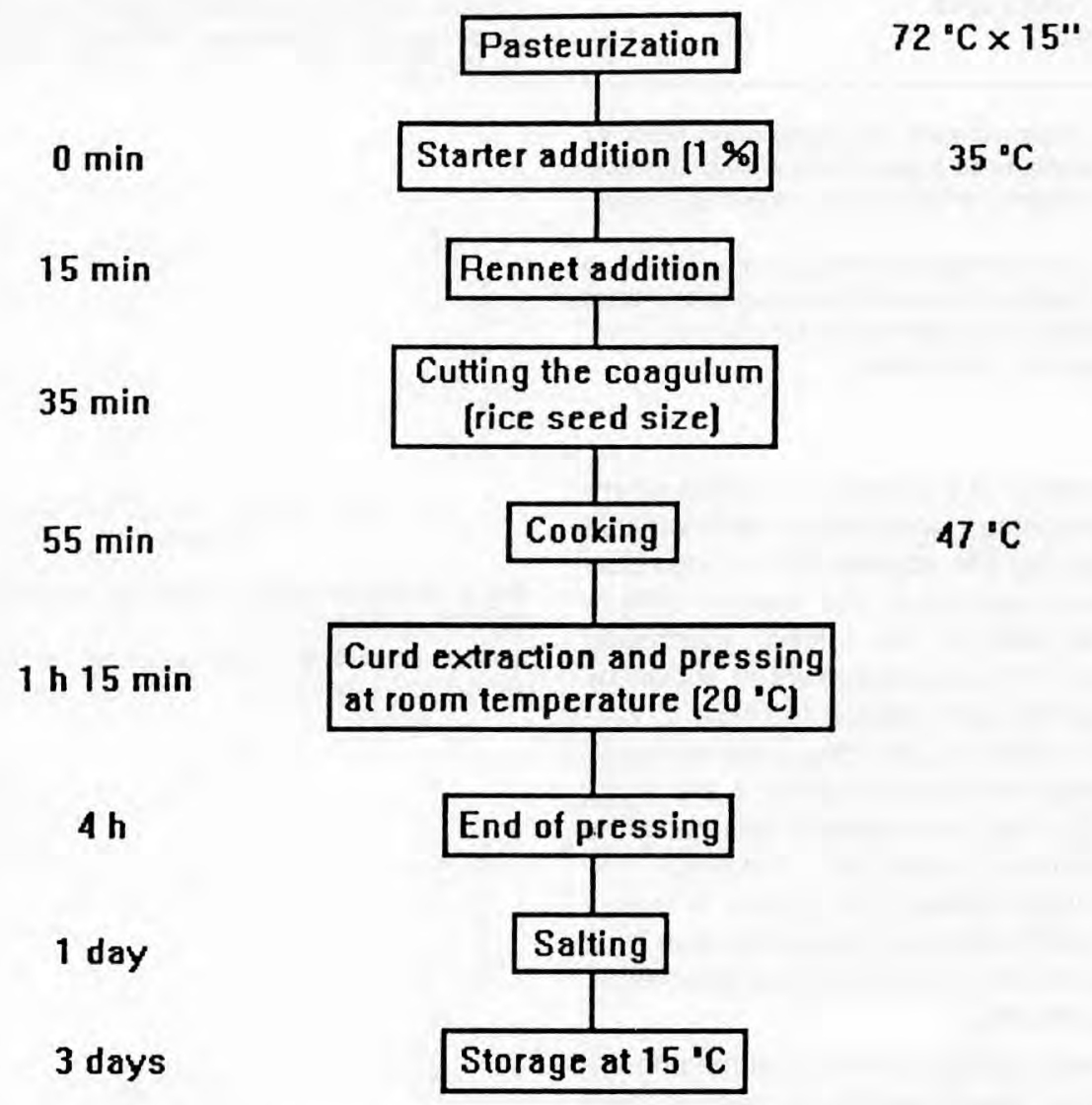

Fig 1. Outline of Montasio cheese manufacture technology, partially modified by pasteurization of milk (no heat treatment is possible with the standard technology).

Schéma de technologie pour la fabrication du fromage Montasio, partiellement modifié par la pasteurisation du lait (aucun traitement thermique n'est permis par la technologie standard). 
Table II. PCA results.

Résultats de l'ACP appliquée aux données.

\begin{tabular}{|c|c|c|c|}
\hline & $w^{(1)}$ & $p_{1}(2)$ & $\mathrm{p}_{2}^{(2)}$ \\
\hline$V_{\mathrm{m}}$ & 0.310 & 0.450 & 0.059 \\
\hline$T_{\mathrm{m}}^{\mathrm{m}}$ & 0.011 & 0.383 & 0.523 \\
\hline$p H_{m}$ & 4.387 & 0.385 & -0.404 \\
\hline$T_{50}$ & 0.04 & 0.412 & 0.482 \\
\hline$p H_{50}$ & 3.425 & -0.349 & 0.550 \\
\hline $\mathrm{pH}_{16}$ & 2.904 & 0.446 & -0.157 \\
\hline $\begin{array}{l}\text { Fraction of variance } \\
\text { explained }\end{array}$ & & 74 & 11 \\
\hline
\end{tabular}

(1) $w=1 / \mathrm{SD}$ represents the multiplicative factor for each variable to be scaled to unit variance (autoscaling). (2) Loading of first $\left(p_{1}\right)$ and second $\left(p_{2}\right)$ component.

(1) $\mathrm{W}=1 / \mathrm{SD}$ représente le facteur de multiplication de chaque variable pour parvenir à une variance unitaire (autoscaling). (2) Chargement de la première $\left(\mathrm{p}_{1}\right)$ et de la deuxième $\left(\mathrm{p}_{2}\right)$ composante.

combination of the original variables where the percentage relevance of each variable is given by the squares of the individual loadings reported in the second column $\left(p_{1}\right)$ of table II. The relative information content of the 6 parameters is shown by the loading plot reported in figure 6 : variables 1 and $6\left(V_{m}\right.$ and $\left.p H_{16}\right)$ exhibit similar behaviour, whereas variables 2 and $4\left(T_{\mathrm{m}}\right.$ and $T_{50}$ ) have independent information as do variables 3 and $5\left(p H_{m}\right.$ and $\left.p H_{50}\right)$. The separation between the groups is mainly due to differences in those variables lying along the first principal component, namely $V_{\mathrm{m}}$ and $\mathrm{pH}_{16}$.

These findings can be confirmed on establishing disjoint models for each of the 3 groups, where the simple baricenter can be taken as a good representation of the cluster. The differences between the groups can be derived thereafter by crossed fitting, as suggested in SIMCA

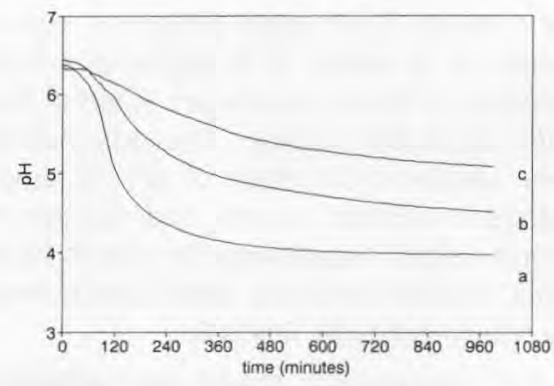

Fig 2. $\mathrm{pH}$ variation as a function of time. Strains a) THT20; b) THT17; c) THT33.

Courbe d'acidification (allure $\mathrm{du} \mathrm{pH}$ par rapport au temps) des souches (a) THT20, (b) THT17 et (c) THT33.

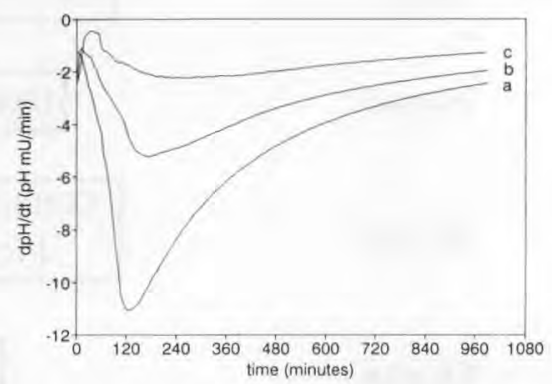

Fig 3. Acidification rates of strains: a) THT20; b) THT17; c) THT33.

Vitesse d'acidification des souches : a) THT20; b) THT17; c) THT33.

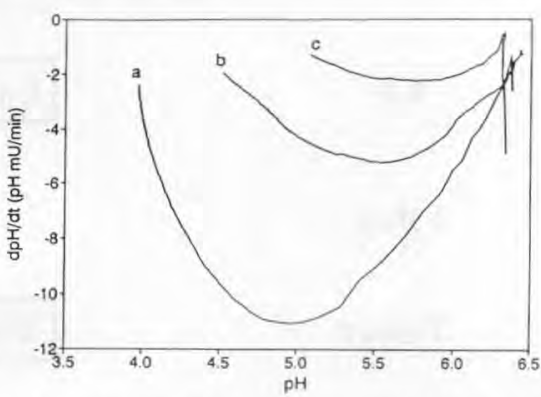

Fig 4. Relationship between acidification rates (dpH/dt) and pH of strains: a) THT20; b) THT17; c) ТHT33.

Relation entre vitesse d'acidification (dpH/dt) et pH des souches : a) THT20; b) THT17; c) THT33. 
(Wold and Sjöström, 1977). These results are summarized in table III, where we have reported the average values for each variable in each group and the discriminant power of each parameter taken pairwise: variables are considered to be discriminating when $D P$ is higher than 3.
It is clear (table III) that the best parameters for identifying the class to which each object belongs are $V_{\mathrm{m}}$ and, slightly worse, $\mathrm{pH}_{16}$, while $\mathrm{pH}$ m proposed by Spinnler and Corrieu for comparison of the strains was shown to be useful only for separation of $F$ and $M$ groups but not of $M$ from $S$.

Table III. Average values for each variable in each group and the discriminant power of each parameter taken pairwise.

Valeurs moyennes de toutes les variables de chaque groupe et pouvoir discriminant des paramètres par chaque couple de classes.

\begin{tabular}{|c|c|c|c|c|c|c|}
\hline & Class (1) $_{F}$ & $\begin{array}{c}\text { Class }^{(1)} \\
M\end{array}$ & $\begin{array}{c}\text { Class }^{(1)} \\
S\end{array}$ & $F M^{(2)}$ & $F S^{(2)}$ & $M S^{(2)}$ \\
\hline$V_{\mathrm{m}}$ & -10.73 & -5.29 & -1.86 & 9.6 & 17.1 & 8.6 \\
\hline$T_{\mathrm{m}}^{\mathrm{m}}$ & 131 & 196 & 394 & 3.2 & 3.9 & 2.9 \\
\hline $\mathrm{pH}_{\mathrm{m}}$ & 5.02 & 5.40 & 5.52 & 4.2 & 3.8 & 1.3 \\
\hline$T_{50}$ & 369 & 709 & 1040 & 6.2 & 4.9 & 2.4 \\
\hline$p H_{50}$ & 2.00 & 1.87 & 1.30 & 1.3 & 3.0 & 2.4 \\
\hline$p H_{16}$ & 3.93 & 4.40 & 4.91 & 5.8 & 5.3 & 3.0 \\
\hline
\end{tabular}

(1) Mean values. (2) Discriminant power given as:

$$
D P=\frac{S_{A V B}^{2}+S_{B / A}^{2}}{S_{A V A}^{2}+S_{B / B}^{2}}
$$

$S_{A / B}=$ variance for each variable when objects of class $A$ are fitted to the model of class $B$;

$S^{2} B / A=$ variance for each variable when objects of class $B$ are fitted to the model of class $A$;

$S_{A / A}^{2}=$ variance for each variable when objects of class $A$ are fitted to the model of class $A$;

$S^{2}{ }_{B / B}=$ variance for each variable when objects of class $B$ are fitted to the model of class $B$;

$D P$ can give an idea of the distance between the 2 classes for each variable. Variables with a $D P>3$ have a strong influence on the separation of the classes.

(1) Valeurs moyennes; (2) pouvoir discriminant exprimé par :

$$
D P=\frac{S_{A / B}^{2}+S_{B / A}^{2}}{S_{A / A}^{2}+S_{B / B}^{2}}
$$

$\mathrm{S}_{\mathrm{A}}^{2} \mathrm{~B}=$ variance de chaque variable quand les éléments de la classe $\mathrm{A}$ sont comparés avec ceux du modèle de la classe $\mathrm{B}$;

$\mathrm{S}_{\mathrm{B} / \mathrm{A}}^{2}=$ variance de chaque variable quand les éléments de la classe $\mathrm{B}$ sont comparés avec ceux du modèle de la classe A;

$\mathrm{S}^{2}{ }_{\mathrm{AA}}=$ variance de chaque variable quand les éléments de la classe $\mathrm{A}$ sont comparés avec ceux du modèle de la classe A;

$\mathrm{S}_{\mathrm{B} / \mathrm{B}}^{2}=$ variance de chaque variable quand les éléments de la classe $\mathrm{B}$ sont comparés avec ceux du modèle de la classe B.

DP peut exprimer la distance entre les 2 classes par chaque variable. Les variables qui présentent $\mathrm{DP}>3$ ont une importante influence sur la séparation des classes. 


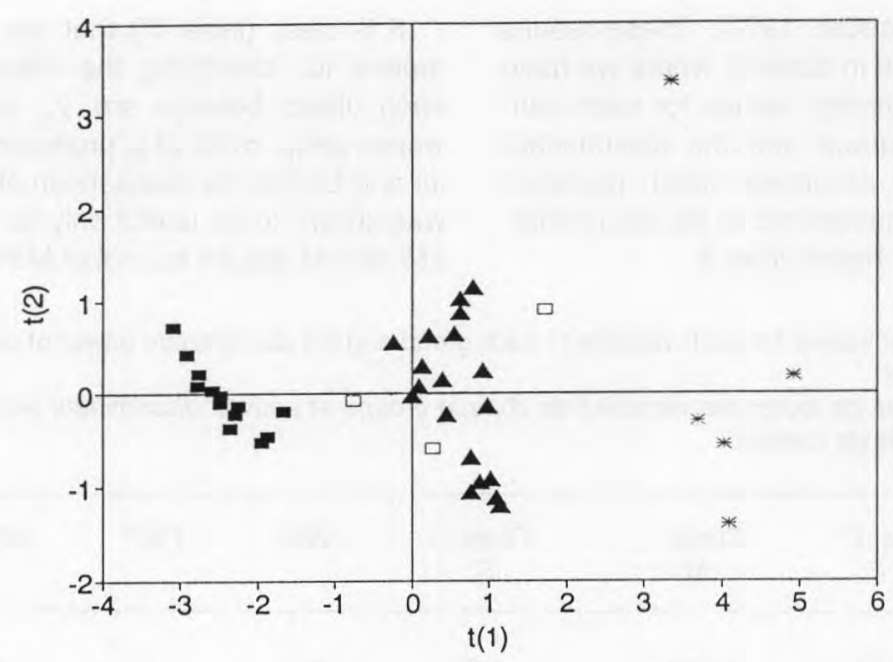

Fig 5. Score plot of the first 2 components, $t(1)$ and $t(2) . F$ strains (full rectangles): THT10, THT11, THT14, THT15, THT16, THT20, THT21, THT22, THT23, THT25, THT26, THT27, THT28. M strains (triangles): THT1, THT2, THT3, THT4, THT5, THT6, THT7, THT8, THT17, THT18, THT19, THT24, THT29, THT30, THT31, THT32, THT38, THT39, THT40. S strains (asterisks): THT9, THT33, THT34, THT35, THT36. Commercial strains (empty rectangles): THT12, THT13, THT37.

Projection du nuage de points sur les axes des composantes, $\mathrm{t}(1)$ et $\mathrm{t}(2)$. Souches $\mathrm{F}$ (rectangles pleins) : THT10, THT11, THT14, THT15, THT16, THT20, THT21, THT22, THT23, THT25, THT26, THT27, THT28. Souches M (triangles pleins) : THT1, THT2, THT3, THT4, THT5, THT6, THT7, THT8, THT17, THT18, THT19, THT24, THT29, THT30, THT31, THT32, THT38, THT39, THT40. Souches S lastérisques) : THT9, THT33, THT34, THT35, THT36. Souches du commerce (rectangles vides) : THT12, THT13, THT37.

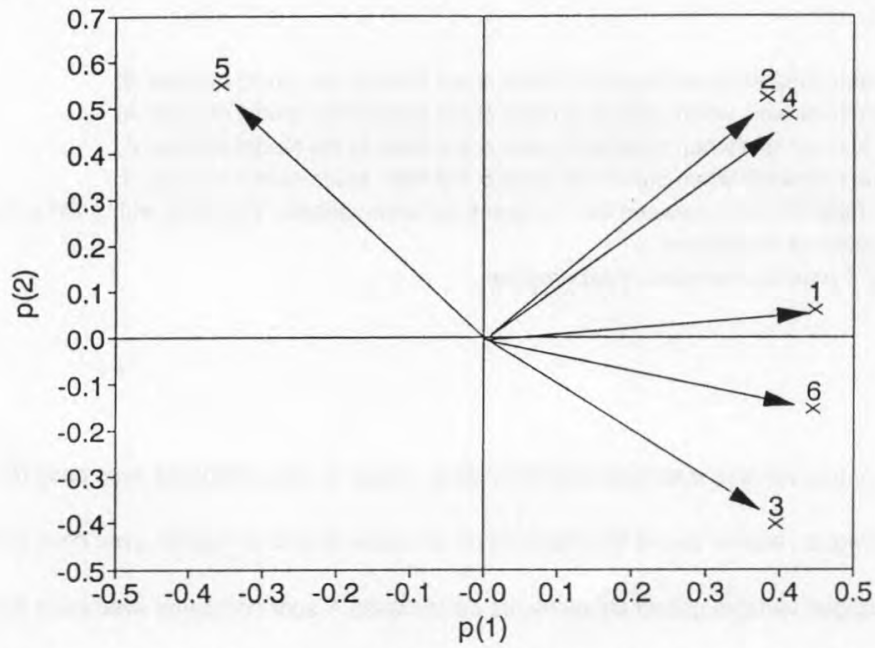

Fig 6. Loading plot of the first ? components $p\left({ }_{1}\right)$ and $p\left({ }_{2}\right) .1=V_{m} ; 2=T_{m} ; 3=p H_{m} ; 4=T_{50} ; 5=p H_{50}$; $6=\mathrm{pH}_{16}$.

Projection des variables sur le plan des composantes $\left.\mathrm{p}_{1}\right)$ et $\mathrm{p}(2)$. 
These arguments show that classification based on single variables may be misleading and only the multivariate approach guarantees a correct classification.

Acidification activity was very high for $F$ strains and was concentrated over a short time period (low $T_{50}$ values), while $M$ strains showed a lower but more regular acid production. Finally, $\mathrm{S}$ strains revealed very low acidification rates and did not ensure a good acid production when used as starters in a cheesemaking process.

Modelling the 37 objects of the training set permits classification of the commercial strains (THT12, THT13 and THT37). Graphically, fitting these 3 new objects to the principal component plane results in the 3 projected points, indicated by empty rectangles in figure 5 , which can be easily interpreted as belonging to class M. Again this finding can be confirmed numerically by measuring the object-model distances between each test set strain and the baricenter (table IV).

Table IV. Object-model distances between each test set strain and baricenters of the 3 classes. Distances de chaque souche du test set des modèles et barycentre des 3 classes.

\begin{tabular}{lccc}
\hline & $\begin{array}{c}\operatorname{Class}^{(1)} \\
F\end{array}$ & $\begin{array}{c}\text { Class }^{(1)} \\
M\end{array}$ & $\begin{array}{c}\text { Class }^{(1)} \\
S\end{array}$ \\
\hline THT12 & 1.28 & 0.36 & 1.76 \\
THT13 & 0.94 & 0.63 & 2.12 \\
THT37 & 1.84 & 0.64 & 2.25 \\
$S_{0}{ }^{(2)}$ & 0.29 & 0.37 & 0.90 \\
\hline
\end{tabular}

(1) Object-baricenter distance. (2) Standard deviation for the reference test $S_{\mathrm{i}}$ (an object can be considered as belonging to the class when $S_{1}<3 S_{0}$ according to an F-test).

(1) Distance souche-modèle. (2) Ecart-type du test de référence $\mathrm{S}_{i}$ (en accord avec $\mathrm{F}$-test, on peut assigner une souche à la classe, lorsque $\mathrm{S}_{1}<3 \mathrm{~S}_{0}$ ).
All 3 commercial strains therefore belong to class $M$, although object THT12 is very close to the average values of the class, while objects THT13 and THT37 are not exactly the same: THT13 differs mainly because of $\mathrm{pH}_{50}$ and THT37 mainly because of $T_{50}$ (results not shown).

To verify the differences observed, performances of some strains belonging to $F$ and $\mathrm{M}$ groups were compared in 2 simultaneous cheesemaking processes. The results confirmed the validity of the classification, since slower rates of acidification and higher final $\mathrm{pH}$ values were obtained in cheese made with $M$ compared to $F$ strains (table V).

\section{CONCLUSIONS}

Data collected in this study show the existence of large differences between Streptococcus salivarius subsp thermophilus strains.

Kinetic parameters allowed a quantitative description of strains in terms of acidification rate, time for maximum acidification rate, $\mathrm{pH}$ value after a definite period. PCA revealed that strains could be differentiated into 3 classes. This statistical method could constitute a valuable tool for their characterization. The input of other information, eg fermented carbohydrate profile, proteolysis products and aromatic compounds, may reveal the existence of subgroups characterized by a good level of homogeneity. Strains with the same technological requirements and different phage resistance properties could be used sequentially to ensure the reproducibility of the cheesemaking process. 
Table V. Summary of data concerning experimental cheese manufacturing. Données résumées des essais de fabrication du fromage.

\begin{tabular}{|c|c|c|}
\hline & \multicolumn{2}{|c|}{ Groups considered } \\
\hline & $\begin{array}{c}F \\
\text { strains }\end{array}$ & $\begin{array}{c}M \\
\text { strains }\end{array}$ \\
\hline & THT2O & THT17 \\
\hline & THT21 & THT18 \\
\hline & THT22 & THT19 \\
\hline & THT23 & \\
\hline Starter acidity $\left({ }^{\circ} \mathrm{SH} / 50\right)$ & 10.0 & 10.0 \\
\hline $\mathrm{CFU} / \mathrm{ml}$ & $3.0 \times 10^{8}$ & $3.2 \times 10^{8}$ \\
\hline $\mathrm{pH}$ of milk after inoculation & 6.54 & 6.54 \\
\hline Time of process (min) & 55 & 55 \\
\hline Curd $\mathrm{pH}$ since draining & & \\
\hline time (min) $\quad 0$ & 6.43 & 6.48 (curd extraction) \\
\hline 10 & 6.22 & 6.32 \\
\hline 100 & 5.51 & 5.82 \\
\hline 180 & 5.20 & 5.36 \\
\hline 240 & 5.18 & 5.36 \\
\hline $24 \mathrm{~h}$ & 5.18 & 5.34 \\
\hline
\end{tabular}

\section{ACKNOWLEDGMENTS}

We are grateful to S Clementi, Professor of Advanced Organic Chemistry (Chemometrics) at Perugia University for helpful discussion and critical reading of this manuscript. We acknowledge the contribution of A Squartini, D Spolaor and $F$ Zilio and the technological team of the institute for assistance in experimental cheesemaking.

\section{REFERENCES}

Accolas JP, Auclair J (1970) Determination of the acid-producing activity of concentrated frozen suspension of lactic acid bacteria. Lait $50,609-626$

Albano C, Dunn III W, Edlund U, Johansson E, Nordén B, Sjöström M, Wold S (1978) Four levels of pattern recognition. Anal Chim Acta $103,429-443$
Clementi S, Cruciani G, Giulietti G, Bertuccioli M, Rosi I (1990) Food quality optimization. Food Qual Prefer 2, 1-2

Cogan TM, Daly C (1987) Cheese starter cultures. In: Cheese: Chemistry and Microbiology (Fox PF, ed) Elsevier Applied Science, London

Coppola S, Villani F, Coppola R, Parente E (1990) Comparison of different starter systems for water-buffalo Mozzarella cheese manufacture. Lait 70, 411-423

Farrow JAE, Collins MD (1984) DNA base composition, DNA-DNA homology and long-chain fatty acid studies on Streptococcus thermophilus and Streptococcus salivarius. J Gen Microbiol 130, 357-362

FIL/DF (1980) Starters used in cheesemaking. Int Dairy Fed Bull 129

Forni E, Carminati D, Colombo F, Bossi MG (1990) Caratterizzazione di ceppi appartenenti alla specie Streptococcus thermophilus. Ind Latte 1, 47-53 
Hardie J (1986) Genus Streptococcus. In: Bergey's Manual of Systematic Bacteriology (Sneath PHA, Mair NS, Sharpe ME, Holt JG, eds) The Williams and Wilkins Co, Baltimore, MD, vol 2, sect 12, 1043-1047

Heap HA, Lawrence RC (1981) Recent modification to the New Zealand activity test for Cheddar cheese starters. N Z J Dairy Sci Technol 16, 91-94

Horral BE, Elliker PR (1947) An activity test for Cheddar and cottage cheese starters. J Dairy Sci 30, 523-524

Jones T, Ozimek L, Stiles ME (1990) Comparative evaluation of bulk starter substrates on activity and storage of two commercial starter strains. J Dairy Sci 73, 1166-1172

Moore WEC, Moore L (1989) Index of the Bacterial and Yeast Nomenclatural Changes. Am Soc Microbiol, Washington

Nielsen J, Nikolajsen K, Villadsen J (1989) FIA on line monitoring of important lactic acid fermentation variables. Biotechnol Bioeng 33, 1127-1134

Spinnler H, Corrieu G (1989) Automatic method to quantify starter activity based on $\mathrm{pH}$ measurement. J Dairy Res 56, 755-764
Terzaghi BE, Sandine WE (1975) Improved medium for lactic streptococci and their bacteriophages. App/ Microbiol 29, 807-813

Wold S, Sjöström M (1977) SIMCA: A method for analyzing chemical data in terms of simi- larity and analogy. In: Chemometrics: Theory and Application (Kowalski BR, ed) ACS Symp Ser 52, Washington

Wold S, Albano C, Dunn III WJ, Esbensen K, Esbensen K, Hellberg S, Johansson E, Sjöström M (1983) Pattern recognition: finding and using regularities in multivariate data. In: Food Research and Data Analysis (Martens $\mathrm{H}$, Russwurm Jr H, eds) Applied Science Publishers, London

Wold S, Albano C, Dunn III WJ, Edlund U, Esbensen K, Geladi P, Hellberg S, Johansson E, Lindberg W, Sjöström M (1984) Multivariate data analysis in chemistry. In: Chemometrics, Mathematics and Statistics in Chemistry (Kowalski BR, ed) D Reided Publ Co, Dordrecht

Wold S, Esbensen K, Geladi P (1987) Principal component analysis. Chemometr Intelligent Lab Syst 2, 37-52 